\title{
Factors Influencing Couples' Unmet Need for Contraception in Kenya
}

\author{
Moses Otieno Omwago \\ Formerly Population Studies and Research Institute (PSRI) \\ University of Nairobi, P.O Box 30197, Nairobi, Kenya. \\ E-Mail:omwagomusa@yahoo.com \\ And \\ Anne A. Khasakhala* \\ Population Studies and Research Institute (PSRI) \\ University of Nairobi, P.O Box 30197, Nairobi, Kenya \\ E-mail:akhasakhala@uonbi.ac.keorakhasakhala@yahoo.com \\ Phone: 254-20-318262 ext. 28029/28031
}

\begin{abstract}
Many studies on unmet need have been women-based with some passing inferences made for men and couples yet reproductive decisions are not made by women alone, but are dyadic in nature. This paper examines couple's unmet need for contraception in Kenya by using the married couple as the unit of analysis, rather than the individual man or woman. The paper specifically estimates couple's unmet need and identifies factors that have influenced this. The data used is from the matched couple data derived from the Kenya Demographic and Health Survey, 1998 (KDHS). Only fecund couples in monogamous unions are included in the analysis. The results give the total couple's unmet need of 16.5 percent (which is 7.5 percent lower than the level of unmet need for currently married women and 3.7 percent higher than the Bankole-Ezeh estimate of couples' unmet need, using 1993 KDHS). About 7 percent of this accounted for unmet need for limiting while 9.8 percent accounted for unmet need for spacing. In terms of factors influencing couple's unmet needs, region of residence, ethnicity, number of living children and couples' discussion of and other reproductive health issues, were the most significant predictors of couples' unmet need. In order to reduce the unmet need, region specific programs should be emphasized and that couple's should be encouraged to make joint decisions on reproductive health issues.
\end{abstract}

Key Words: Kenya, unmet need, reproductive health, contraception, couple, family planning 


\section{Introduction}

The concept of unmet need evolved in the 1960's when data from surveys of contraceptive knowledge, attitude and practice (KAP) showed that a considerable number of women were not using contraceptives despite their desire to space and stop childbearing. This discrepancy, the 'KAP-gap' was later to be referred to as the unmet need for contraception (Westoff, 1978). Subsequent data from World Fertility Surveys (WFS), Contraceptive Prevalence Survey (CPS), and Demographic and Health Surveys (DHS) helped to refine the concept further (Nortman, 1982; Westoff, 1978; 1988; Westoff and Ochoa, 1991; Westoff and Pebley, 1981; Westoff and Bankole, 1995; Nortman and Lewis, 1984; Westoff, 1994; Casterline and Sinding, 2000; Ngom, 1997; Robey et al., 1996).

These early studies of unmet need, however, focused mainly on married women due to a number of factors that include the fact that women had been the central focus of research since they were more directly involved in reproduction; methods for women were more developed, and that, as opposed to men, they were more motivated to adopt contraception. Recently, some researchers have embarked on extensive study of men's role in (Ngom, 1997; Nzioka, 1998; Mbizvo and Adamchak, 1991; Posner and Mbodji, 1989; Omondi-Odhiambo, 1997; Onyango, 2001; Otieno, 2000). These studies have not however, improved our knowledge and understanding of family planning practice as a dyadic process involving the support, cooperation and agreement of both partners. Just as the woman has been central in family planning, so should the man since he may fail to give consent for such practice, or fail to cooperate in using methods like the natural method. Therefore using women's data to make conclusions on unmet need status of couples may be grossly misleading. 
Elsewhere, studies have shown that programs aimed at couples do better than those targeting individual men or women (Terefe and Larson, 1993; Fisek and Sombuloglu, 1978; Becker, 1996). This study argues for a reorientation of unmet need to the couple-based approach. The reorientation is expected to reduce the level of unmet need considerably (Bankole and Ezeh, 1999).

\section{Context}

Everyday more than 400,000 conceptions take place around the world; of which about half are deliberate while the other half, are unintentional (Potts, 2000). In Kenya, over half of the population growth is accounted for by unwanted fertility (Kekovole, 1996). In the past two decades, Kenya has achieved a considerable increase in contraceptive use, resulting in an appreciable decline in fertility. Contraceptive Prevalence Rates have increased from a mere 7 percent in 1977 to 27 percent in 1989; 33 percent in 1993; 39 percent in 1998 and 2003 respectively. Despite these achievements, the level of unmet need still remains high. This implies that couples`control over reproduction is far from perfect, and as a result, the number of undesired births is substantial. About 24 percent of the women interviewed in the KDHS 1998 said that they wanted either to postpone or to avoid childbearing but were not using contraceptives.

Since most researches on unmet need have been based on women, there is need to explore a couple-based approach to the phenomenon. This approach has become relevant due to the evidence that men and women have different fertility preferences (Bankole, 1995; Ezeh, 1993). Furthermore, the paradigm shift for family planning to a broader concept of Reproductive Health including Sexually Transmitted Infections (STIs) and HIV/ AIDS has made it necessary to use data from both men and women (Becker, 1996). 
Consequently, the sexually active couple is found to be the most appropriate unit for the study of unmet need.

Unmet need for family planning is multifaceted and cannot be deciphered clearly if individuals are treated in isolation. This is because the desire for and timing of additional children and contraceptive practice are influenced by extra-individual factors, such as ability to communicate, lack of knowledge, societal disapproval and husband's approval (Ngom, 1997). The ICPD Program of Action encouraged reproductive health care programs to move away from considering men and women separately and to adopt a more holistic approach that includes men and focuses on couples (UN, 1995).

Very few studies on the couple unmet need have been done (Bankole and Ezeh, 1999; Becker, 1999; Dodoo, 1993). In Kenya, Bankole and Ezeh used data from KDHS 1993 to estimate the level of couple unmet need which according to them was 12.8 percent after reclassifying the pregnant and amenorrheric couples. They included only a limited number of background factors - education, age and type of residence. The last factor they included was type of marriage. More studies are needed in this field.

\section{Data and Methods}

The study utilized data from the Kenya Demographic and Health Survey (KDHS, 1998). Currently pregnant and amenorrhea couples were excluded from the analysis. The rationale for excluding the couples in which the wife is either pregnant or amenorrhea was in a bid to revert back to the original formulation of unmet need- that they are not currently exposed to the risk of becoming pregnant regardless of the planning status of their pregnancies (West off and Pebley, 1981). Bong arts (1991) argued that including this group would overestimate the level of unmet need. Furthermore, it negates 
the point-in-time principle of the measurement of unmet need that ought to be taken into consideration (Bankole and Ezeh, 1999).

The idea of including the pregnant women in unmet need category is problematic, since women who are pregnant are less likely to state that their pregnancies are unwanted or mistimed (Northman, 1982). Postpartum amenorrhea has been noted not to guarantee perfect protection from getting pregnant (Northman, 1982). This is because ovulation can occur prior to resumption of the menses. Several studies have found out that women conceived during postpartum amenorrhea (WHO, 1981: Billewicz, 1979). According to Northman (1982), women should not rely on postpartum amenorrhea beyond the very early months of birth. West off (2000), in one of his recent publications has suggested the exclusion of the pregnant and the amenorrhea women from the measurement of unmet need (West off, 2000). It is with these considerations in mind that these two groups of couples were excluded in this study.

The study only considered monogamous couples since polygamous husbands were not asked in the KDHS whether they wanted to space or limit births or use contraceptives with each of the wives. Moreover, the majority of births occurred in monogamous unions (Becker, 1999). Out of the 1362 matched couples, 90 percent were monogamous.

Descriptive statistics were used to describe the basic features of the data, bivariate analysis to show association between the unmet need for limiting and spacing and socio-demographic and intermediate variables while logistic regression was used to identify predictors of total unmet needs of couples. The conceptual model used in the study has been adopted from Casterline et al. (1997). The modification made on the Casterline framework was the inclusion of socio-demographic factors. 
This paper has attempted to describe the levels of unmet need for spacing, limiting and total unmet need among couples by socio-demographic characteristics such as age, education, region of residence, and type of place of residence; and to identify the factors that may predict total unmet need among couples in Kenya.

\section{RESULTS}

\section{The magnitude of couple's unmet need in Kenya.}

This section presents the results of the magnitude of unmet need. Figure 1 below shows the algorithm used in defining unmet need among monogamous-fecund couples. Out of the 1362 matched couples in the 1998 KDHS, 1170 were monogamous. The monogamous couples were grouped into four categories; the pregnant, fecund, in fecund and amenorrhea. Among all the couples, 12.2 percent of the women were pregnant. 6.1 percent of the pregnancies were intended, 4.7 percent mistimed, and 1.3 percent unwanted. For the amenorrhea, 9.5 percent of the cases were those where the last child was intended, 8.1 percent were intended but later, while 2.7 percent were not intended at all. These two categories were not included in the estimation of the level of couples' unmet need. The infecund formed 12.6 percent of all the monogamous couples. 


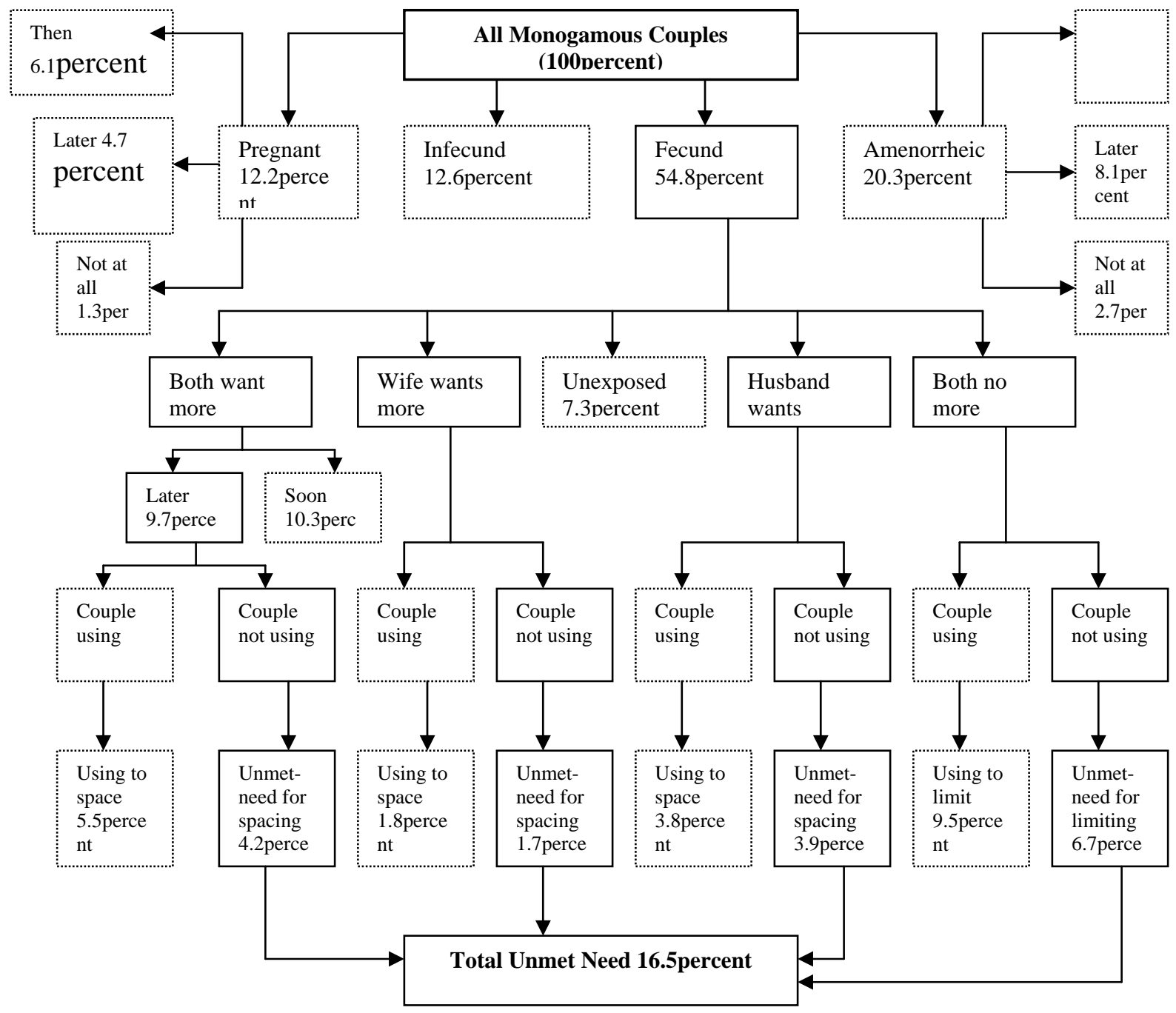


Fig 1: Algorithm for defining those with unmet need for spacing or limiting and total unmet need: Adapted from Bankole and Ezeh (1996:16)

Estimation consisted of fecund couples only, which formed the remaining 54.8 percent. This category was grouped further according to the fertility preferences. The proportion of couples where both wanted to stop child bearing was 16.2 percent. A further 31.2 percent were those couples that wanted more children, either both or only one partner. Of the couples that wanted more children, 20 percent were cases where both partners wanted more, 3.5 percent where only the wife wanted more, and 7.7 percent where only the husband wanted more. The remaining 7.3 percent were unexposed, that is, either sterilized, declared infecund, or never had sex. Among those who wanted more (both partners), 10.3 percent wanted a child soon while 9.7 percent wanted later. The former had no need for contraception, since they want a child immediately. About 7 percent had unmet need for limiting since they wanted no more children yet they were not using contraceptives. Those who were using contraceptives were doing so for limiting purposes.

Where only the husband wanted more children, and none of them was not using contraceptives, then the couple had unmet need for spacing (3.9 percent) and those who were using (3.8 percent) were using for spacing purposes. Among couples where only the wife wants more children, 1.8 percent were using contraceptives (for spacing), and 1.7 percent were not using contraceptives and therefore had unmet need for spacing. Couples where the partner wanted more children later 5.5 percent were using contraceptives (for spacing) and 4.2 percent were not using thus having unmet need for spacing. The total couples' unmet need was therefore found to be 16.5 percent. Bankole and Ezeh (1999) had estimated the couple's unmet need using KDHS 1993 at 12.8 percent after reclassifying pregnant and ammenorrheic women. My estimate is 3.7 percent higher than the 
Couple Unmet Need in Kenya ${ }^{\text {http://aps.journals.ac.za }}$

Bankole-Ezeh estimate. Out of the 16.5 percent, about 7 percent was accounted for by unmet need for limiting while the rest (9.8 percent), for spacing.

\section{Unmet Need for Contraception}

The table below presents the bivariate results of couples who had unmet need for contraception by selected socio-demographic and proximate variables. 
Couple Unmet Need in Kenya ${ }^{\text {http://aps.journals.ac.za }}$

Table 1: Percent Distribution of couples by level of unmet need for contraception by selected socio-demographic and proximate variables

\begin{tabular}{|c|c|c|c|}
\hline Variables & Spacing & Limiting & Total \\
\hline \multicolumn{4}{|l|}{ Background variables } \\
\hline \multicolumn{4}{|l|}{ Province } \\
\hline Nairobi & 6.7 & 6.7 & 13.3 \\
\hline Central & 8.1 & 12.2 & 20.3 \\
\hline Coast & 32.9 & 7.6 & 40.5 \\
\hline Eastern & 10.2 & 13.9 & 24.1 \\
\hline Nyanza & 21.3 & 12.8 & 34.0 \\
\hline Rift Valley & 14.1 & 15.8 & 29.9 \\
\hline Western & 33.3 & 6.9 & \\
\hline \multicolumn{4}{|l|}{ Place of residence } \\
\hline Urban & 17.7 & 7.3 & 25.0 \\
\hline Rural & 18.0 & 13.3 & 31.3 \\
\hline \multicolumn{4}{|l|}{ Husband's education } \\
\hline No education & 39.1 & 8.7 & 47.8 \\
\hline Primary & 20.6 & 15.1 & 35.7 \\
\hline Secondary+ & 13.7 & 9.4 & 23.1 \\
\hline \multicolumn{4}{|l|}{ Wife's education } \\
\hline No education & 31.3 & 20.3 & 51.6 \\
\hline Primary & 18.5 & 12.6 & 31.1 \\
\hline Secondary+ & 12.7 & 8.8 & 21.6 \\
\hline \multicolumn{4}{|l|}{ Ethnicity } \\
\hline Mijikenda/Swahili & 42.5 & 12.5 & 55.0 \\
\hline Kalenjin & 12.5 & 17.9 & 30.4 \\
\hline Kamba & 16.7 & 10.6 & 27.3 \\
\hline Kikuyu/Meru/Embu & 12.0 & 12.0 & 24.0 \\
\hline Kisii & 9.1 & 6.8 & 15.9 \\
\hline Luhya & 24.2 & 8.1 & 32.3 \\
\hline Luo & 24.6 & 16.9 & 41.5 \\
\hline Other & 20.5 & 7.7 & 28.2 \\
\hline \multicolumn{4}{|l|}{ Husband's age } \\
\hline$<25$ & 25.9 & 0.0 & 25.9 \\
\hline
\end{tabular}


Couple Unmet Need in Kenya ${ }^{\text {http://aps.journals.ac.za }}$

$\begin{array}{llll}25-34 & 22.3 & 4.7 & 27.0 \\ 35+ & 14.2 & 18.3 & 32.5 \\ & & & \\ \text { Wife's age } & & & 30.8 \\ <25 & 27.4 & 3.5 & 26.4 \\ 25-34 & 15.6 & 10.8 & 33.5 \\ 35+ & 11.5 & 22.0 & \\ & & & 26.8 \\ \text { Religion } & & & 30.8 \\ \text { Catholic } & 14.3 & 12.5 & 29.2 \\ \text { Protestant } & 18.0 & 12.9 & 42.9 \\ \text { Muslim } & 29.2 & 0.0 & \\ \text { Other } & 33.3 & 9.5 & \end{array}$

No. of living children

$\begin{array}{llll}0-2 & 20.3 & 2.4 & 22.7 \\ 3-5 & 18.7 & 13.6 & 32.3 \\ 6+ & 12.0 & 27.8 & 39.8\end{array}$

Proximate variables

No. of methods wife knows

$<3 \quad 23.4$

3-5 16.7

13.3

36.7

$6+$

13.8

12.4

29.0

23.0

No. of methods husband knows

$<3$

22.2

12.4

24.6

3-5

16.2

12.2

28.4

$6+$

12.5

11.3

23.8

Husband discussed FP with wife

Never 19.8

17.2

37.1

Once or twice

24.9

12.1

37.0

More often

13.3

10.4

23.6

Wife discussed FP with husband

Never

22.1

17.6

39.7

Once or twice

15.2

9.8

25.0

More often

18.5

11.6

30.1

Approval of FP

Disapproves

24.5

16.3

40.8

Approves

17.0

12.0

29.0 


\section{Total unmet need}

The results in table 1 above indicate that Western and Coast provinces had the greatest total unmet need while Nairobi experienced the least. Couples in the rural areas have greater total unmet need than their urban counterparts. Unmet need seemed to decline with increased education. Those with no education had the greatest unmet need. Mijikenda/Swahili ethnic groups that inhabit coast province had the highest level of unmet need followed by the Luo, while Kisii had the lowest. Husbands and wives who were in the $35+$ age group had the highest total unmet need. However, while unmet need increased with husband's age, it did fluctuate with wife's age. Catholics exhibited the lowest unmet need followed by the Muslims. Total unmet need increased with the couple's number of living children. However, it decreased with the increased number of methods known to wife. For the husbands, this fluctuated, with those who knew 3-5 methods having the highest. Couples who had never discussed family planning or disapproved of it had the highest total unmet need.

\section{Unmet need for Spacing}

Couples who had greatest spacing need were from Western, rural, had no education, Mijikenda/Swahili, aged below 25, other religion, and had 0-2 children. Couples who knew less methods ( $<3$ methods) had the highest unmet need for spacing, while those who knew more methods had the lowest levels of unmet need for spacing. Husbands who discussed family planning with their wives once or twice had greater unmet need for spacing (24.9 percent) while those who discussed often had the lowest unmet need (13.3 percent). However, for the wives, those who never discussed with their husbands had the highest unmet need for spacing. Couples who 
disapproved of family planning had higher unmet need for spacing than those who approved, that is, 24.5 and 17.0 percent respectively.

\section{Unmet need for limiting}

Unmet need for limiting was highest among couples from Rift Valley, rural areas, husbands with primary education, wives without any education, Kalenjin, aged 35 and above, protestant, and had 6 or more living children. Indeed, older couples and those who already had many children were likely to want to stop childbearing, contrary to existing literature. Couple who knew few methods or never discussed family planning with partner, or disapproved of family planning had the highest unmet need for limiting as compared to those who knew more methods, discussed family planning often or approved of family planning use.

\section{Predictors of Couples' Unmet Need}

This section presents the results from multivariate analysis. Three models were run in this analysis. The dependent variable was total unmet need because in the previous section the algorithm produced sparse data to allow for running of separate models for limiting and spacing. The first model consisted of only the socio-demographic variables run against the dependent variable, total unmet need. The second model involved running the intermediate variables against the dependent variable, while the third and final model consisted of both the socio-demographic and the proximate variables, but omitting those that were found to be statistically insignificant in the individual models. 


\section{Model One}

Levels of unmet need vary substantially according to demographic and social characteristics, (Robey et al., 1996). Table 2 shows the results of logistic regression for a model which includes socio-demographic characteristics of the couples. The results show that couples in all ethnic groups were less likely to have unmet need than those of Mijikenda/Swahili (reference category). The ethnic differences in unmet need reflect variation in levels of contraceptive use and stage in fertility transition. It further compares well with the results of the regions, whereby areas with low fertility and high contraceptive prevalence are less likely to have high unmet need. It is important to note here that with the exception of Nairobi, regions such as Eastern, Central, and Rift Valley are predominantly inhabited by the ethnic groups that also are less likely to have higher unmet need. For example, Central Province is inhabited mainly by Kikuyus, Eastern by Kamba, Meru and Embu while the Kalenjin are mainly in the Rift Valley. Nairobi being cosmopolitan with access to health facilities and other services is also less likely to have unmet need.

With regard to education, only women with secondary and above level seemed to matter however, Husband's educational level did not appear to matter. This highlights the importance of female education but only when it is above primary level. As expected, the higher the number of living children, the more likely is the unmet need. The odds of unmet need were 3.1 times higher in women with six or more children and 2.4 times higher in women with between three and five children. It shows an increase in the unmet need with increase in the number of children. Couples with higher number of living children may have reached their desired family size goals hence more likely to prefer use of contraception.

Table 2: Logistic regression model for total unmet need (with background variables) 
Couple Unmet Need in Kenttp://aps.journals.ac.za

http:/

\begin{tabular}{|c|c|c|c|c|}
\hline Variable & Std Error & $\operatorname{EXP}(\beta)$ & Std & Error \\
\hline \multicolumn{5}{|l|}{ Ethnicity } \\
\hline Mijikenda/Swahili & 0.0000 & 1.0000 & & \\
\hline Kalenjin & -1.7450 & $0.1746^{*}$ & 0.5503 & \\
\hline Kamba & -0.7572 & 0.4690 & 0.4096 & \\
\hline Kikuyu/Meru/Embu & -1.0832 & $0.3385^{*}$ & 0.7358 & \\
\hline Kisii & -3.3596 & $0.0347^{* * *}$ & 0.5167 & \\
\hline Luhya & -2.3433 & $0.0960^{* * *}$ & 0.6133 & \\
\hline Luo & -1.6215 & $0.1976^{* *}$ & 0.6690 & \\
\hline Other & -1.1256 & $0.3245^{*}$ & 0.5180 & \\
\hline \multicolumn{5}{|l|}{ Religion } \\
\hline Other (reference) & 0.0000 & 1.0000 & & \\
\hline Catholic & -0.0984 & 0.9063 & 0.5850 & \\
\hline Protestant & -0.0170 & 0.9831 & 0.5704 & \\
\hline Muslim & -0.9526 & 0.3858 & 0.7490 & \\
\hline \multicolumn{5}{|l|}{ Wife's level of education } \\
\hline No education (reference) & 0.0000 & 1.0000 & & \\
\hline Primary & -0.5013 & 0.6057 & 0.3269 & \\
\hline Secondary+ & -0.7923 & $0.4528^{* *}$ & 0.3829 & \\
\hline \multicolumn{5}{|l|}{ Husband's education } \\
\hline No education (reference) & 0.0000 & 1.0000 & & \\
\hline Primary & 0.1167 & 1.1238 & 0.4977 & \\
\hline Secondary+ & -0.3864 & 0.6795 & 0.5217 & \\
\hline \multicolumn{5}{|l|}{ Place of residence } \\
\hline Rural (reference) & 0.0000 & 1.0000 & & \\
\hline Urban & -0.0352 & 0.9654 & 0.3318 & \\
\hline \multicolumn{5}{|l|}{ Region of residence } \\
\hline Western (reference) & 0.0000 & 1.0000 & & \\
\hline Nairobi & -2.1567 & $0.1157^{* * *}$ & 0.8343 & \\
\hline Central & -2.2226 & $0.1083^{* * *}$ & 0.6679 & \\
\hline Coast & -1.7469 & $0.1743^{* *}$ & 0.7457 & \\
\hline Eastern & -2.3153 & $0.0987^{* * *}$ & 0.6641 & \\
\hline Nyanza & -0.5133 & 0.5985 & 0.7096 & \\
\hline
\end{tabular}


Couple Unmet Need in Kenya ${ }^{\text {http://aps.journals.ac.za }}$

$\begin{array}{llll}\begin{array}{l}\text { Rift Valley } \\ \text { Wife's age }\end{array} & -1.3938 & 0.2481^{* * *} & 0.5249 \\ <25 \text { (reference) } & 0.0000 & 1.0000 & \\ 25-34 & -0.3086 & 0.7344 & 0.3125 \\ 35+ & -0.4165 & 0.6594 & 0.4028 \\ & & & \\ \text { Husband's age } & & & \\ <25 \text { (reference) } & 0.0000 & 1.0000 & 0.4270 \\ 25-34 & 0.3700 & 1.4477 & \\ 35+ & 0.1532 & 1.1656 & \\ & & & 0.4892 \\ \text { No. of living children } & & & \\ 0-2 \text { (reference) } & 0.0000 & 1.0000 & \\ \text { 3-5 } & 0.8753 & 2.3996^{* * *} & \\ \text { 6+ } & 1.1454 & 3.1438^{* * *} & \\ -2 \text { log likelihood } & 704.395 & & \\ \text { Model Chi-Square } & 79.199 & & \\ \text { Significance } & 0.0000 & & \\ \text { df } & 27 & & \end{array}$

Note: ${ }^{*} p<0.10 \quad{ }^{* *} p<0.05 \quad{ }^{* * *} p<0.01$

\section{Model Two}

Several reasons combined may explain why there are unmet need among couples such as, lack of information and spousal communication on issues relating to family planning or contraceptive use (Robey et al 1996). Table three below presents the results of the model when only intermediate variables are considered. The results indicate that the likelihood of having unmet need seems to decrease with the number of methods of family planning known to couples. Couples who knew 6 or more methods were less likely to have unmet need as compared with those who knew less than 3 methods. Further, spousal communication is important but the results are rather erratic. 
Couple Unmet Need in Kentp://aps.journals.ac.za

Table 3: Logistic regression model for total unmet need (with intermediate variables)

\begin{tabular}{|c|c|c|c|}
\hline Variable & $\beta$ & $\operatorname{EXP}(\beta)$ & STD Error \\
\hline \multicolumn{4}{|l|}{ Approval of FP } \\
\hline Disapproves (reference) & 0.0000 & 1.0000 & \\
\hline Approves & -0.2253 & 0.7983 & 0.3386 \\
\hline \multicolumn{4}{|c|}{ No. of methods wife knows } \\
\hline$<3$ (reference) & 0.0000 & 1.0000 & \\
\hline $3-5$ & -0.2990 & 0.7416 & 0.2157 \\
\hline $6+$ & -0.5618 & $0.5702^{*}$ & 0.3206 \\
\hline \multicolumn{4}{|c|}{ No. of methods husband knows } \\
\hline$<3$ (reference) & 0.0000 & 1.0000 & \\
\hline $3-5$ & -0.1869 & 0.8295 & 0.1969 \\
\hline $6+$ & -0.2696 & 0.7636 & 0.3139 \\
\hline \multicolumn{4}{|l|}{ Wife discusses FP } \\
\hline Never (reference) & 0.0000 & 1.0000 & \\
\hline Once or twice & 0.5447 & $0.5800 * *$ & 0.2471 \\
\hline Often & -0.0997 & 0.9051 & 0.2550 \\
\hline \multicolumn{4}{|l|}{ Husband discusses FP } \\
\hline Never (reference) & 0.0000 & 1.0000 & \\
\hline Once or twice & 0.0801 & 1.0834 & 0.2614 \\
\hline Often & 0.5064 & $0.6027^{* *}$ & 0.2467 \\
\hline-2 log likelihood & 733.845 & & \\
\hline Model Chi-Square & 26.151 & & \\
\hline Significance & 0.0019 & & \\
\hline $\mathrm{df}$ & 9 & & \\
\hline
\end{tabular}

Note: ${ }^{*} p<0.10 \quad{ }^{* *} p<0.05$ 
Couple Unmet Need in Kenya ${ }^{\text {http://aps.journals.ac.za }}$

\section{Model Three}

Model three involved combination of both socio-demographic and intermediate variables in the regression equation. Only variables that were statistically significant in model one and two were included. The results are presented in Table 4 below. In this model the aim was to see what variables remained significant when socio-demographic and intermediate variables were combined. The results have shown that the variables that were significant in the individual models retained their levels of significance in the combined model. The changes were only in the co-efficient.

The persistent significance of region and ethnicity may not be fully explained here given that data on density (availability) of family planning outlets, relative costs (both economic and social) are not included in Demographic and Health Surveys (DHS). Similarly information on time dependent variables such as wife and husband discussion of family planning cannot be fully explained here as the actual time of discussion and behaviour change are not easy to link (Robey et al., 1996). 
Couple Unmet Need in Kenya ${ }^{\text {http://aps.journals.ac.za }}$

Table 4: Logistic regression analysis for total unmet need (with both background and intermediate variables)

\begin{tabular}{|c|c|c|c|}
\hline Variable & $\beta$ & $\operatorname{EXP}(\beta)$ & $\begin{array}{l}\text { Std } \\
\text { Error }\end{array}$ \\
\hline \multicolumn{4}{|l|}{ Region of residence } \\
\hline Western (reference) & 0.0000 & 1.0000 & \\
\hline Nairobi & -2.1493 & $0.1166^{* * *}$ & 0.7562 \\
\hline Central & -2.4056 & $0.0902^{* * *}$ & 0.6740 \\
\hline Coast & -1.5739 & $0.2072^{* *}$ & 0.6909 \\
\hline Eastern & -2.2403 & $0.1064^{* * *}$ & 0.6588 \\
\hline Nyanza & -0.3267 & 0.7213 & 0.6961 \\
\hline Rift Valley & -1.2000 & $0.3012^{* *}$ & 0.5179 \\
\hline \multicolumn{4}{|l|}{ Ethnicity } \\
\hline Mijikenda/Swahili (reference) & 0.0000 & 1.0000 & \\
\hline Kalenjin & -1.3927 & $0.2484^{* *}$ & 0.6431 \\
\hline Kamba & -0.5176 & 0.5959 & 0.6081 \\
\hline Kikuyu/Meru/Embu & -0.7370 & 0.4785 & 0.6012 \\
\hline Kisii & -2.7669 & $0.0629^{* * *}$ & 0.8637 \\
\hline Luhya & -1.9085 & $0.1483^{* * *}$ & 0.7377 \\
\hline Luo & -1.4256 & $0.2404^{*}$ & 0.7557 \\
\hline Other & -0.9409 & $0.3908^{*}$ & 0.5667 \\
\hline \multicolumn{4}{|l|}{ No. of living children } \\
\hline $0-2$ (reference) & 0.0000 & 1.0000 & \\
\hline $3-5$ & 0.6193 & $1.8577^{* * *}$ & 0.2231 \\
\hline $6+$ & 0.8095 & $2.2469^{* * *}$ & 0.2600 \\
\hline \multicolumn{4}{|l|}{ Wife's level of education } \\
\hline No education (reference) & 0.0000 & 1.0000 & \\
\hline Primary & -0.4030 & 0.6683 & 0.3120 \\
\hline Secondary + & -0.9229 & $0.3974^{* * *}$ & 0.3506 \\
\hline \multicolumn{4}{|c|}{ Wife discusses FP with husband } \\
\hline Never (reference) & 0.0000 & 1.0000 & \\
\hline Once or twice & -0.5033 & $0.6045^{* *}$ & 0.2568 \\
\hline Often & -0.1116 & 0.8944 & 0.2610 \\
\hline \multicolumn{4}{|c|}{ Husband discusses FP with wife } \\
\hline Never (reference) & 0.0000 & 1.0000 & \\
\hline Once or twice & 0.0905 & 1.0947 & 0.2781 \\
\hline Often & -0.5199 & $0.5946^{* *}$ & 0.2629 \\
\hline-2 log likelihood & 690.778 & & \\
\hline Model Chi-Square & 82.461 & & \\
\hline Significance & 0.0000 & & \\
\hline
\end{tabular}

Note: ${ }^{*} \mathrm{p}<0.10 \quad * * \mathrm{p}<0.05 \quad{ }^{* * *} \mathrm{p}<0.01$ 


\section{Discussion}

The study set out to estimate the level of unmet need using a 'couple approach', and to determine the significant factors affecting couple unmet need. The results have show that the level of unmet need for couples was much lower than that of married women or men separately, that is, 16.5 percent as compared to 24 and 23 percent for women and men respectively. It is evident that incorporating men in the estimation of unmet need is important in reducing the level of unmet need. Intermediate factors, acting on their own, may not (satisfactorily) explain couple's unmet need, except for discussion of family planning.

Although socio-demographic factors were important in determining couple's unmet need, some of them proved rather insignificant, for example, religion. Religion has been shown in other studies as a key factor that may determine the use of family planning, particularly Catholic and Muslim. The same case applies with place of residence, age and husband's education. When both husband's and wife's education were put in the same model, husband's education became insignificant, suggesting that wife's level of education was more important if couple's unmet need were to be reduced.

The high levels of unmet need in Nyanza, Western and Coast are consistent with the fact that the same regions also experience low contraceptive prevalence rates and consequently high fertility rates, as compared to Nairobi, Central and Eastern. In the 1998 KDHS, the contraceptive prevalence rate in Central and Nairobi were 61 and 56 percent, while Coast and Nyanza were 22 and 28 percent respectively. The results are consistent with earlier studies. Cross (1990) found women from Western province to have the highest unmet need. Omondi-Odhiambo (1997) has documented that couples in Nairobi, Central and Eastern (where conformity to traditional reproductive practices are weaker), are more likely to use contraception and 
hence have lower unmet need than those who live in patriarchal communities of Nyanza, Coast, Western and Rift Valley.

The likelihood of having unmet need seemed to increase with the number of living children. Couples who have more living children are more likely to have unmet need than the ones who have fewer children or none at all. Couples with more children have a greater desire to stop childbearing, which may not be translated into actual practice, because of other factors affecting the decision to use family planning, or those that affect the supply and accessibility of family planning. However, the argument is that, just as those who have more children have unmet need (for limiting), so do those who have fewer children (for spacing). Furthermore, unmet need for spacing is higher than that for limiting. Wafula (2001) also found unmet need to be high among women with more children.

The study conformed to the expectation that wives with higher levels of education had low levels of unmet need, since they were capable of transforming their desire (to space or to limit) into practice (of using family planning). Couples who are more educated can afford to buy contraceptives, are more likely to reside in the urban areas where contraceptives are more accessible, are more informed about the available methods and are more likely to prefer smaller families than their less educated counterparts. 


\section{Conclusion}

In the light of the above discussion, the level of unmet need is reduced substantially, when couples are considered (i.e., 16.5 percent) as opposed to when women alone approach is adopted (i.e. 24 percent). This finding attests the fact that standard definition of unmet need overestimates the level of unmet need. In view of the determinants of couples' unmet need, wife's variables (education level, methods known to wife and discussion of FP) were found to be more significant than some of the husbands' variables, affirming the imperative place of the women in any reproductive health strategy.

Since region of residence was one of the most important determinants of unmet need according to the findings, the conclusion here is that different programme strategies should target different regions since the factors working against the adoption of contraceptives, or rather against the translation of the need to use contraception into actual practice are different and region-specific. Husband and wife discussion of family planning is important for the approval of family planning and eventual practice of a method. It provides the fertile ground on which couples can implement their fertility desires and contraceptive need.

Another research area is the factors determining couple discussion of family planning. As husband and wife communication increasingly takes centre stage in studies on unmet need there is need to document some of these factors which affect communication between couples.

In a nutshell, the prevalence of high unmet need in Kenya is an upshot of diverse constraints imposed on both women and men in their efforts to achieve their fertility preferences and hence their inability to practice contraception. This situation is the cause of high rates of unwanted fertility 
Couple Unmet Need in Kenya ${ }^{\text {http://aps.journals.ac.za }}$

and population growth. If the ongoing fertility transition is to be enhanced, unmet need should be tackled appropriately. The prevalence of unmet need reflects a lag in the implementation of couples' fertility decisions due to inhibiting constraints to the use of contraception. Such constraints must be eliminated first in any meaningful strategy. 


\section{References}

Bankole, A. (1995). "Desired Fertility and Fertility behaviour among the Yoruba of Nigeria: A Study of Couples' Preferences and Subsequent Fertility." Population Studies, 49(2): 317 - 328.

Bankole, A. and Alex C. Ezeh (1999), "Unmet Need for Couples: Conceptual Framework and Evaluation with DHS data." African Population and Health Research Center; Working Paper No. 12, Population Council.

Becker Stan (1999) “Measuring Unmet Need: Wives, Husbands or Couples?" International Family Planning Perspectives, 25(4): 172-180.

Becker, S. (1996). "Couples and Reproductive Health: a Review of Couple Studies." Studies in Family Planning, 27(6): 291 - 306.

Bongaarts, J. (1991). "The KAP-Gap and the Unmet Need for Contraception." Population and Development Review, 17(2): 293-313.

Casterline, J.B. and S.W. Sinding (2000). "Unmet Need and Implications for Population Policy." Population and Development Review, 26(4) 291-723.

Casterline, J.B., A.E. Perez and A.E. Biddlecom (1997). "Factors Underlying Unmet Need in the Philippines." Studies in Family Planning, 28(3): 173-191.

Dodoo, F.N-A, (1993), "The Couple KAP - gap: implications for in Developing Countries." Paper Presented at the Annual meeting of the Population Association of America, Cincinnati, 1-3 April.

Ezeh, A. C. (1993). “The Influence of Spouses over each other's Contraceptive attitudes in Ghana." Studies in Family Planning, 24(3) 167 - 174.

Fisek, Nusret H. and K. Sumbuloglu (1978) "The Effects of Husband and Wife Education on in rural Turkey" Studies in Family Planning, 9, 10/11: 280-285.

Karanja, S.M (1997)" Unmet Need for Contraception and their Demographic Significance in Kenya," Unpublished MA Thesis, University of Nairobi.

Kekovole, J. (1998). “Trends and Correlates of Unmet Need for Contraception in Kenya: Findings and Implication for Fertility Transition." African Population Policy Research Center, Working Papers No. 5. Population Council.

Mbizvo, M. T. and D.J. Adamchak (1991). "Knowledge, Attitudes and Practices of Men in Zimbabwe." Studies in Family Planning, 22(1): 31-38.

NCPD, CBS and Macro International (1994). Kenya Demographic and Health Survey, 1993 
NCPD, CBS and Macro International (1999). Kenya Demographic and Health Survey, 1998

Ngom, P (1997). "Implications of Men's Unmet Need in Africa." Studies in Family Planning,, 28(3): 192-202.

Nortman, D.L. (1982). "Measuring unmet need for contraception to space and limit births." International Family Planning Perspectives, 8(4); 125-134.

Nzioka, C. (1998). "Factors Influencing Male Interest in Kenya." African Journal of Reproductive Health, 2(2); 122-141.

Omondi-Odhiambo (1997). “Men's Participation in Decisions in Kenya." Population Studies, 51(1): 29-40.

Onyango, F.O (2001) “Unmet Need for Contraception among Men in Kenya: evidence from KDHS 1998" Unpublished MA Thesis, University of Nairobi.

Otieno, O.P (2000) “Men's Knowledge, Attitude and Practice of Family Planning in Kenya" Unpublished MA Thesis, University of Nairobi.

Posner, J.J. and F. Mbodji (1989). “Men's attitudes about in Dakar, Senegal." Journal of Biosocial Science, 21(3) 279 - 291.

Potts, M (2000). “The unmet Need for.” Scientific American, 2000: 88-93.

Robey, B., J. Ross, and I. Bushan (1996). "Meeting unmet need: new strategies." Population Reports, Series J, 43.

United Nations (1995). International Conference on Population and Development (ICPD 1994). New York: The UN

Westoff, C. F. and A. Bankole (2000). "Trends in the demand for Limitation in Developing Countries." International Family Planning Perspectives, 26(2): 56 - 62 \& 97.

Westoff, C. F. (1988). "Is the KAP-gap real?" Population and Development Review, 14(2): $225-232$.

Westoff, C. F. and A. Bankole (1995). "The Potential Demographic Significance of Unmet Need." International Family Planning Perspectives, 22(1): 16-20.

Westoff, C. F. and A. Pebley (1981). “Alternative Measures of Unmet Need for in developing Countries.” International Family Planning Perspectives, 7(4): 126-136.

Westoff, C.F. (1978). "The Unmet Need for Birth Control in five Asian Countries." International Family Planning Perspectives, 10(3): 173 - 181. 